\title{
PREGNANCY PLUS HIV and pregnancy
}

\author{
Glenda E Gray, James A McIntyre
}

Perinatal HIV Research Unit, University of the Witwatersrand, Johannesburg, South Africa Correspondence to: G E Gray gray@pixie.co.za

BMJ 2007:334:950-53 doi: 10.1136/bmj.39176.674977.AD
This is one of a series of occasional articles about how to manage a pre-existing medical condition during pregnancy. If you would like to suggest a topic for this series please email Kirsten Patrick kpatrick@bmj.com
The management of HIV infection during pregnancy is complex, and the scenario box on this page illustrates the complexities involved. In 2005, UNAIDS (the Joint United Nations Programme on HIV/AIDS) estimated that 38.6 million people had HIV, of whom 17.3 million were women (with most being in their reproductive years). At least 3.28 million pregnant women infected with HIV are estimated to give birth each year, with more than 75\% of these in sub-Saharan Africa; this is where most of the annual 700000 new infections of HIV in children occur.

\section{Timing of and factors affecting mother to child transmission}

Perinatal transmission of HIV can occur in utero, during labour and delivery, or postnatally through breastfeeding. ${ }^{1 \text { wl }}$ Most transmission occurs during the intrapartum period. ${ }^{1}$ Transmission will vary from less than $2 \%$ in the developed world (with its access to antiretroviral therapy, caesarean section, and formula milk) to more than $30 \%$ in the developing world (where access to therapy is limited and breastfeeding is prolonged). ${ }^{\text {w2 }}$ Observational studies have shown that the risk of perinatal transmission is affected by maternal stage of disease; duration of rupture of membranes; increased genital secretion of HIV associated with sexually transmitted infections such as herpes simplex virus; and other factors such as prematurity. Large randomised controlled studies have shown that mother to child transmission can be reduced by the use of antiretroviral therapy, elective caesarean section, and exclusive formula feeding. ${ }^{2}$

How does pregnancy affect progression of HIV disease? Pregnancy does not adversely affect HIV progression or survival. ${ }^{3 \text { w3-w7 }}$ Dual infection with HIV and malaria has been associated with increased risk of maternal, perinatal, and early infant death. ${ }^{\text {w8 }}$ Improved access to care, treatment, and nutritional support in resource limited settings may help to reduce poor pregnancy outcomes. The decline in the CD4 cell count during pregnancy normally resolves in the postpartum period and is attributed to haemodilution. ${ }^{45 \text { w9-w11 }}$ Although HIV RNA levels seem to remain stable during pregnancy, some studies have shown an increase in viral load in the postpartum period. ${ }^{\text {w11 }}$

In developed countries, with easy access to specialist care, HIV infection is a rare cause of maternal

\section{SCENARIO}

A 27 year old woman is referred to the antenatal clinic at 16 weeks of pregnancy. This is her second pregnancy-her first child, delivered by caesarean section, is now 8 years old. The mother was diagnosed with HIV four years ago when she developed herpes zoster. She has been taking zidovudine, lamivudine, and nevirapine for four weeks through an antiretroviral treatment access programme. At the time of starting treatment, her CD4 count was $124 \times 10^{6}$ cells/l, her viral load 50000 copies $/ \mathrm{ml}$, and her haemoglobin $104 \mathrm{~g} / \mathrm{l}$. She had received a negative screening result for tuberculosis and was receiving daily co-trimoxazole prophylaxis for preventing opportunistic infections. At the 16 week visit she was found to have a haemoglobin concentration of $87 \mathrm{~g} / \mathrm{l}$. She is from an African community and has not disclosed her HIV status to her family; she is concerned about the possible stigma associated with not breast feeding her infant.

\section{Comments}

- It is important to establish whether the woman's first child was infected with HIV (or whether the child ever had an HIV test), and what her partner's HIV status is

- As her first delivery was via a caesarean section, this would be the preferred method for her second baby

- At 34 weeks her viral load and CD4 count should be repeated to ensure she has undetectable viraemia and that her CD4 count has responded to therapy

- Even though nevirapine is recommended for women of reproductive potential, efavirenz might have been started. Efavirenz has been associated with neural tube defects in both human and non-human primates

- Of concern in this case, is the worsening anaemia. If zidovudine is the cause of this anaemia, she should switch to stavudine. However, stavudine has additional complications when used in pregnancy-such as lactic acidosis, so the patient should be warned of this potential side effect and taught to identify its signs and symptoms

- She should be seen more often by her physician and referred for psychological counselling on the importance of disclosure of her status, to ensure that she is supported in infant feeding choices

mortality. In contrast, HIV infection has become an important contributing cause of maternal mortality in Africa. ${ }^{6}{ }^{\mathrm{w}} 12$ In areas of high HIV prevalence, the infection has become a leading cause of maternal mortality. Several reports from southern African countries have shown this trend, including maternal mortality rates 
Box $1 \mid$ Antiretroviral regimens for preventing mother to child transmission of HIV-1 (adapted from the British HIV Association)

\section{Zidovudine monotherapy}

- From 18 weeks of pregnancy

- If viral load <6000-10 000 HIV RNA copies/ml plasma

- If virus is wild-type

- If highly active antiretroviral therapy (HAART) is not required for maternal health

- If mother does not wish to take HAART during pregnancy

- If mother is willing to deliver by elective caesarean section

Effective ( $\geq 3$ drug) combination therapy

- Indicated for maternal health as per adult guidelines

- If baseline maternal viraemia $>10000$ copies $/ \mathrm{ml}$

- If baseline maternal viraemia <10 000 copies/ml if an alternative is required to zidovudine monotherapy plus pre-labour caesarean section

- If drug resistance is detected on genotype/phenotype

- Avoid nevirapine as part of combination therapy if CD4 count is $>250 \times 10^{6}$ cells $/ \mathrm{l}$

Short term HAART for prevention of mother to child transmission

- Discontinue this after delivery when viral load $<50$ copies $/ \mathrm{ml}$

- Carefully consider the half-life of each component to avoid unplanned monotherapy after stopping, especially drugs with a low genetic barrier to resistance

Stavudine plus didanosine

- Avoid stavudine plus didanosine whenever possible

HAART started before conception

- Usually this should be continued throughout pregnancy

Detailed anomaly ultrasound

- Consider a detailed anomaly ultrasound examination at 21 weeks for all fetuses exposed to antiretrovirals during the first trimester team of clinicians, psychologists, and social workers will optimise care. In women who know their HIV status, prepregnancy counselling may optimise medical care and minimise adverse outcomes.

In many resource poor areas, tuberculosis is a common opportunistic infection in pregnant women with HIV, so it should be excluded in these settings or in women who have recently arrived in a developed country from a developing one. Laboratory investigations, in addition to routine tests in pregnancy, should include liver function tests, complete blood count (including platelet count and lymphocyte subsets), plasma HIV RNA viral load, and screening for sexually transmitted infections. Where hepatitis screening is not one of the routine investigations, then hepatitis B testing should be offered to women from areas with a high prevalence of HIV infection, and hepatitis $\mathrm{C}$ screening should be considered if intravenous drug use is common.

Antiretroviral therapy can be used in pregnancy (according to a country's guidelines) when indicated as an ongoing treatment for maternal health; when not needed for this indication, it can be provided for preventing mother to child transmission. If antiretrovirals are indicated for maternal health, the choice of regimen should ensure that maternal side effects and risks to the infants are minimised. Dosage modification is not required for nucleoside reverse transcriptase inhibitors and nevirapine. Efavirenz should be avoided during early pregnancy because of teratogenic neural tube defects seen in both primates and humans. ${ }^{7}$ The combination of didanosine and stavudine should be avoided in pregnancy because of lactic acidosis. Nevirapine should be avoided in women with $\mathrm{CD} 4$ counts $>250 \times 10^{6}$ cells $/ 1{ }^{8}$ When antiretroviral therapy is used for preventing mother to child transmission, regimens range from the use of triple antiretroviral therapy to zidovudine started antenatally, with or without peripartum nevirapine (box 1). Post-exposure prophylaxis should be started at birth (box 2). of the maternal deaths.

\section{How does HIV affect pregnancy and pregnancy outcomes?}

Observational studies have shown that HIV infection is associated with varying rates of adverse pregnancy outcomes, such as increased spontaneous abortion, stillbirth, perinatal and infant mortality, intrauterine growth retardation, low birth weight, and chorioamnionitis. ${ }^{\text {w13- }}$ ${ }^{\text {w16 }}$ HIV infection may also reduce fertility, irrespective of stage of infection. ${ }^{\text {w17 }}$ In Uganda HIV infected women have lower pregnancy rates and more pregnancy losses than uninfected women. ${ }^{\text {w17 }}$ Some studies have found larger intervals between pregnancies and an association between high viral loads and difficulty in conceiving. ${ }^{\text {w18 }}$

\section{How can HIV be managed in pregnancy?}

Antenatal care provides an opportunity to counsel pregnant women about HIV risk and offer HIV testing. The management of a pregnant woman with HIV infection will depend on the resources available and the individual needs of the woman; a multidisciplinary

\section{Clinical management of labour and delivery}

The British HIV Association recommends an elective caesarean section for women receiving zidovudine alone; those receiving combination therapy with detectable viraemia; and those with HIV and hepatitis $\mathrm{C}$ coinfection. ${ }^{9}$ Observational data have shown that caesarean section may be associated with a slightly higher risk of postoperative complications in women with HIV than in uninfected women and that frequent complications such as postpartum fever, endometritis,

Box 2 Antiretroviral prophylaxis for infants exposed to HIV-1 (adapted from the British HIV Association)

- Most infants should be given zidovudine monotherapy for four to six weeks

- Alternative suitable monotherapy may be given if maternal therapy does not include zidovudine

- Triple therapy should be considered as post-exposure prophylaxis for infants born to untreated mothers or mothers with detectable viraemia despite combination therapy 


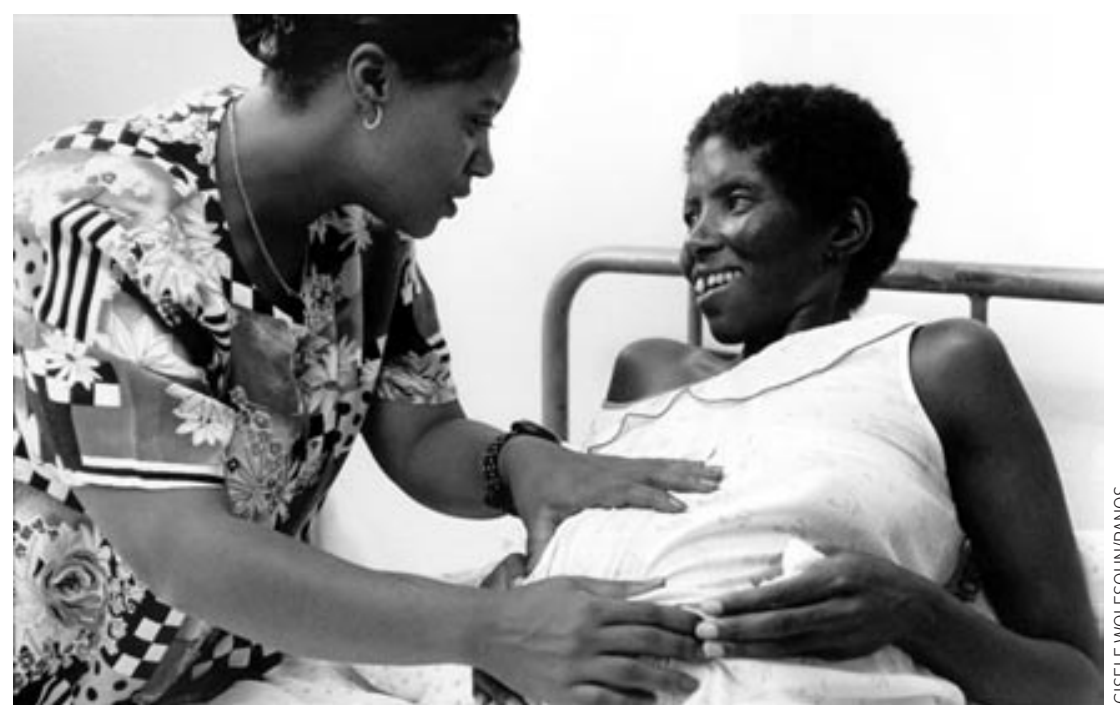

wound infection, and pneumonia occur significantly more often in infected women. ${ }^{\text {w19-w21 }}$

Although the use of elective caesarean section has been a major factor in reducing the rates of mother to child transmission in well resourced settings, it may not be a feasible option in many less resourced areas of high HIV prevalence. In these areas, some cases might merit a lowered threshold for caesarean section; such cases would include any pregnancies where labour is expected to be prolonged or where other obstetric complications may be associated with increased transmission risk (such as abruptio placentae and preterm rupture of membranes). Depending on the available facilities, this may also apply to women who had had previous caesarean sections or breech presentations.

When caesarean section is not performed, care in labour should focus on minimising the risk of mother to child transmission. This risk is increased with increased duration of rupture of membranes. As artificial rupture of membranes has little obstetric benefit in normal labour, it should not be done routinely in women who are known to be HIV positive or in areas of high HIV prevalence. In the case of premature rupture of membranes, with or without labour, the risk of HIV transmission must be balanced against the risk of premature delivery.

Invasive fetal monitoring techniques such as penetrating or spiral scalp electrodes and fetal scalp blood sampling may create a portal of entry for the virus and ought to be avoided. Episiotomy may increase the exposure of the infant to HIV during delivery and increase the risk of transmission. Routine episiotomy is not recommended, and it should be reserved for those cases with a clear obstetric indication. Assisted delivery by forceps or vacuum extraction carries a theoretical possibility of increasing the risk of transmission through damage to the baby's skin. Little information exists on the contribution of obstetric procedures to the risk of transmission in the presence of antiretroviral therapy.

\section{Postpartum complications}

In most HIV positive women the postnatal course will be uncomplicated and no special medical care will be needed. Postpartum complications encountered more often in HIV positive women include puerperal sepsis, infected episiotomies, massive condylomata acuminata, urinary tract infections, pneumonia, fever, tuberculosis, and unusual infections.

\section{What about breast feeding?}

Breast feeding is an important route of transmission. In the United Kingdom, where safe infant feeding alternatives are available, HIV infected women are advised to refrain from breast feeding. In resource poor settings where breast feeding is essential for infant survival, exclusive breast feeding for four to six months may be justified.

\section{Diagnosis in infants}

In non-breastfed infants, HIV infection can be diagnosed definitively at age 6-12 weeks using DNA polymerase chain reaction. In some settings, such testing is done at birth to exclude in utero transmission of HIV-1, and this test is repeated at age 6 weeks and 12 weeks to exclude transmission that may have occurred in the intrapartum and postpartum period. If the mother is breast feeding her infant, HIV testing can start one month after weaning, with a second test eight weeks later. ${ }^{10}$

\section{Conclusion}

Preventing HIV infection in children has become possible in the past decade. Interventions exist for minimising mother to child transmission of HIV, both in the developed and the developing world. If these are widely implemented in the next decade, they will result in a substantial decline in the number of children acquiring this devastating disease from their mothers.

\section{ADDITIONAL EDUCATIONAL RESOURCES}

Guidelines for management of HIV and hepatitis C coinfection in adults www.bhiva.org/guidelines/2004 HCV/index.htm

British HIV Association. Guidelines for the management of HIV infection in pregnant women and the prevention of mother-to-child transmission of HIV. London: BHIVA, 2005. www.bhiva.org/guidelines/2005/pregnancy/index.htm

Guidelines for management of HIV and hepatitis B coinfection in adults www.bhiva.org/guidelines/2004 HBV/index.htm

World Health Organization. HIV-infected women and their families: psychosocial support and related issues. A literature review. 2003. Www.who.int/reproductive-health/ publications/rhr_03_07/

Department of Health. HIV and infant feeding. Guidance from the UK ChiefMedical Officers' Expert Advisory Group on AIDS. 2004. www.advisorybodies.doh.gov.uk/eaga (then follow HIV link)

World Health Organisation. Integrated management of pregnancy and childbirth. Managing complications in pregnancy and childbirth: a guide for midwives and doctors. Geneva: WHO, 2000. (WHO/RH/00.7) 
Contributors: GE Gray was responsible for the conception, development, and overall writing of the article; she is also the guarantor. JAMcl provided the case report, gave obstetrical input, and helped to edit the manuscript. Competing interests: None declared.

Provenance and peer review: Commissioned; externally peer reviewed.

1 Mofenson LM. Mother-child HIV-1 transmission: timing and determinants. Obstet Gynecol Clin North Am 1997;24:759-84.

2 Gray GE, McIntyre JA. Effect of HIV on women. AIDS Reader 2006;16:365-8, 373-7.

3 Saada M, Le Chenadec J, Berrebi A, Bongain A, Delfraissy JF, Mayaux MJ, et al. Pregnancy and progression to AIDS: results of the French prospective cohorts. SEROGEST and SEROCO Study Groups. AIDS 2000;14:2355-60.

4 Burns DN, Nourjah P, Minkoff H, Korelitz J, Biggar RJ, Landesman S, et al. Changes in CD4+ and CD8+ cell levels during pregnancy and post partum in women seropositive and seronegative for human immunodeficiency virus-1. Am J Obstet Gynecol 1996;174:1461-8.

5 Tuomala RE, Kalish LA, Zorilla C, Fox H, Shearer W, Landay A, et al. Changes in total, $\mathrm{CD} 4+$, and $\mathrm{CD} 8+$ lymphocytes during pregnancy and 1 year postpartum in human immunodeficiency virus-infected women. The Women and Infants Transmission Study. Obstet Gynecol 1997;89:967-74.

6 Lewis G. Confidential enquiries into maternal deaths: beyond the numbers: reviewing maternal deaths and complications to make pregnancy safer. Geneva: World Health Organization, 2004:77-102.

7 Mofenson LM. Efavirenz reclassified as FDA pregnancy category D. AIDS Clin Care 2005;17(2):17.

8 US Food and Drug Administration. FDA Public Health Advisory for Nevirapine (Viramune). 19 January 2005. www.fda.gov/cder/drug/ advisory/nevirapine.htm,

9 British HIV Association. Guidelines for the management of HIV infection in pregnant women and the prevention of mother-to-child transmission. HIV Medicine 2001;2:314-34.

10 World Health Organization. New data on the prevention of mother-to child transmission of HIV and their policy implications, conclusions, and recommendations. WHO technical consultation on behalf of the UNFPA/UNICEF/WHO/UNAIDS Inter-Agency Task Team on Motherto-Child Transmission of HIV, Geneva, 11-13 October 2000. Geneva: WHO, 2001.

\title{
A PATIENT'S JOURNEY Psoriasis
}

\author{
Ray Jobling
}

Psoriasis Association, 7 Milton
Street, Northampton NN2 7JG rgj1000@cam.ac.uk

BMJ 2007:334:953-4 doi: $10.1136 /$ bmj.39184.615150.802
In 1955, I was 14 years old and just diagnosed with psoriasis. I didn't know it then of course, but it would never go away. Psoriasis and its treatment were to be part of my life for the next 50 years and more.

My general practitioner gave it no name, but said it was common and could just go away. He said I might "grow out of it" and that I should get used to it, "learn to live with it." This attitude scarcely prompted confidence in his prescribed tar ointments and baths-as noxious and loathsome in use as they were ineffective in action. He seemed unsurprised that I returned worse rather than better. By now the pink patches were large, numerous, and widespread. My body looked like an old map of the British Empire. The lesions grew fiery, scaled profusely, and crumbled messily. They bled; I looked and felt a mess.

I was dispatched to a dermatologist. I had psoriasis-no more information let alone an explanation was forthcoming. I was to redouble my ointmenting efforts. Perhaps, it was alleged, my (the family's) compliance had not been strict enough, a ludicrous accusation for we were dutifully dedicated to the demanding daily rituals of topical treatment. We pressed on for months. Tar gave way to anthralin (dithranol), which stained me as much as my clothing and bed linen. Life was punctuated by endless clinic encounters with a bewildering succession of skin doctors. I was repeatedly, rather routinely, told that I was not ill and must not think of myself as such. I had to live a normal life. It was after all no more than a "benign" condition. Later, I heard a dermatologist tell his students as I departed the consultation, "Not very interesting that one, just another very ordinary psoriasis." If there was any awareness of the practical, psychological, and social complexities involved, no explicit interest was shown, and neither assistance nor advice was offered.
Not ill then, but obviously a permanent patient, I found myself in a strange and perplexingly ambiguous position. For someone who was not ill-I was otherwise in robust rugby playing good health in fact-I spent a puzzling amount of time in consulting rooms or clinics and labouring away at treatment. The demanding treatment regimens, which at times took more than 20 hours a week, brought scant reward. "Clearance" seemed to be the goal, but even improvement was only ever partial and dispiritingly temporary-remission was impossible. I was engaged in a relentless physical assault on my symptoms, at war with my skin . . . and inevitably losing. The disease and its treatment merged, combining inextricably to impact upon my personal experience and social identity; a sad fact that both were in effect demeaning. Skin disease can stigmatise. Stripped of my clothes I looked strangely, perhaps threateningly, different. I understandably attracted unwanted attention. Although rare, revulsion and rejection were an ever present threat. What appeared to be breadcrumbs were scattered through my hair. I shed a constant shower of scaly detritus, leaving my mark wherever I went. Daily applied tar meant that I smelled like a newly paved road. If it rained my hair gave off a sickly odour. Even my winter tan (derived from treatment) set me apart. No one from my world jetted to beaches or ski slopes in the $1950 \mathrm{~s}$.

Thus, I grew up with it. Years and life unfolded, offering new opportunities and experiences, but also demanding adjustments. I had long wanted to join the Navy. No one doubted my physical fitness. I spent months competing for officer selection, but I was inevitably rejected on medical grounds-I was hugely disappointed. Those who had insisted that psoriasis was not an illness had neglected to tell me that it could still be a handicap. I took my psoriasis and its treatment 